\title{
A Comparison of Responses to the Eastern and Western Instruments on Transformational and Transactional Leadership 透過文化觀點比較東西方轉型領導與交易領導問卷
}

Ying-Hua HUNG

Physical Educational Office, National Formosa University,

Chinese Taipei, TAIWAN

Chin-Tsai KUO

Department of Tourism Management, Naanhua University,

Chinese Taipei TAIWAN

\section{洪櫻花}

台灣國立虎尾科技大學體育室

郭進財

台灣南華大學旅遊事業管理學系

\author{
Annette E. CRAVEN \\ University of the Incarnate Word, \\ School of Business, \\ Texas, U.S.A.
}

\section{Suh-Ting LIN}

Physical Educational Office,

Tamkang University,

Chinese Taipei TAIWAN

\section{安妮卡芬}

美國得州聖道大學商學院

\section{林素婷}

台灣淡江大學體育室

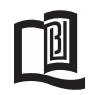

\begin{abstract}
The purpose of this study was to compare the responses of Eastern and Western instruments toward the transformational and transactional leadership. A quantitative survey and qualitative interview was used in this study. The participants included 57 directors, 285 followers, and 6 interviewees from Taiwanese universities. The results showed the transformational leadership had a significant positive correlation ( $\mathrm{rs}=.81, \mathrm{p}<.01$ ) between the MLQ-5X (rater form) and the TFLQ. Transactional leadership also had a significant positive correlation ( $r s=.47, \mathrm{p}<.01$ ) between the MLQ-5X and the TSLQ. The summarized conclusions were the following: First, similar results indicated that both the MLQ-5X and the TFLQ/TSLQ were effective in the Taiwanese environment. Second, same leadership concepts may have contained specific thoughts, beliefs, understandings, or behaviors in one culture but not another; however, the concepts of transformational leadership may seem similar in different cultures but may be expressed differently.
\end{abstract}

Key words: culture, instruments, transformational and transactional leadership

\section{摘 要}

轉型領導與交易領導行為是一種全球化的概念, 但在不同的文化背景下, 或許會有不同的詮釋。本研究採用西方學者所創立 的「多元領導行為」問卷(MLQ-5X)，以及台灣學者所創立的本土化的「多元領導行為」問卷(TFLQ與TSLQ)，透過量化的問卷調 查與質性的訪談研究, 探討台灣地區大專院校體育室主任的領導行為。研究結果顯示, 不同的東西方轉型領導與交易領導問卷研 究結果具有一致性。

關鍵詞：不同文化, 轉型領導, 交易領導 


\section{Introduction}

Leadership is a universal human phenomenon, which involvs interpersonal influence or persuasion of others, and helps people achieve certain actions and goals. Cultural values and beliefs play a significant role in shaping customs within organizations. It also affects the practice of leadership development, which relates to the values, beliefs, hopes, and fears of human existence (Dong \& Liu, 2010). National cultures differ primarily in their values and organizational cultures differ mainly in their practices. "Foreign theories can no doubt serve as a source of inspiration, but they should be reconceptualized according to the best of the local traditions" (Hofstede, 2001, p. 387). Although transformational and transactional leadership styles include universal concepts and components, the specific behaviors involved may be different, particularly as one cross into the non-Western world (Bass, 1997).

Bass developed the original Multifactor Leadership Questionnaire (MLQ) in 1985. The theory base of the MLQ is an extension by Bass of the theory developed by Burns (1978) on transformational and transactional leadership styles. Contrary to Burns, Bass views transformational and transactional leadership as a continuum (Bass, 1985). The full-range of leadership includes three dimensions of leadership behaviors identified in the MLQ: transformational leadership, transactional leadership, and laissez-faire leadership behaviors. Additionally, the MLQ evaluates the followers' extra effort, organizational effectiveness, and followers' satisfaction with their leaders.

The MLQ includes three factors. One is the transformational leadership behavior: charisma and inspiration, intellectual stimulation, and individual consideration. The second one is the transactional leadership behaviors: contingent reward, and active management-by-exception. The final one is laissez-faire leadership behavior. Those leadership behaviors continuum in the Full-Range of Leadership Model, which ranges from ineffective to effective leadership, passive to active leadership, and varying frequency continuums for different leadership behaviors. (Bass \& Avolio, 2000; Den Hartog, Van Muijen, \& Koopman, 1997).

Most of the research on transactional and transformational leadership theory has used the MLQ to measure leadership behaviors. However, it still suffers from some response biases according to Bass and Avolio's theoretical and empirical research (Tracey \& Hinkin, 1998; Den Hartog et al., 1997; Avolio, Bass \& Jung, 1999). Although there remain some challenges to the MLQ instrument, it is without a doubt an instrument that offers an integration of diverse perspectives on the full range of leader behavior, follower reactions, and situational attributes (Tracy \& Hinkin, 1998; Tejeda, 2001).

Leaders must understand their own values and ensure, through their consistent behavior, that they reflect their values and share their vision with the followers (Pielstick, 1998). The dominant Chinese values, which stand between individualism and collectivism are tolerance of others, harmony with others, non-competitiveness, close friendships, trustworthiness, contentment with one's position in life, solidarity with others, and being conservative (Hofstede, 2001). Whereas individualism is more dominant in the U.S., collectivism is more the norm in the Chinese culture (Hoppe, 1998). The cultyre-specific perspective suggests that individual's woth different cultural values may perceive leadership differently, such as Asian country like Taiwan. (Spreitzer, Perttula, \& Xin, 2005). Taiwan has a culture grounded in Confucian ideology, which emphasize a strong respect for hierarchy whether in work or family, preserving interpersonal harmony, and exhibiting personal modesty.

Transformational leadership is more readily used and pervasive in the collectivistic societies of East Asia than in the individualistic societies of the West. Transformational leadership has more facilitative influence on the organizational attitudes toward values, rewards, innovations, change, development, and individual respect (Avolio, Waldman, \& Yammarino, 1991; Bass, 1995).

Wu \& Lin (1998) developed a Taiwanese grass-roots Transformational Leadership Questionnaire (TFLQ) and Transactional Leadership Questionnaire (TSLQ) for Chinese managers based on Bass's transformational leadership theory. The TFLQ identifies the transformational leadership style and the TSLQ identifies the transactional leadership style. Both of these instruments also used open-ended questions to collect the managers' transformational and transactional leadership behavior information in the beginning of the questionnaire development. These instruments have been authenticated through the use of pilot studies and factor analyses with sampling groups among Taiwanese businesses and schools. 
Different countries have easier communicated with each other in the higher technology. However, they may show different way by their culture especially in leadership. The questionnaire of Western culture may have some gaps when use in Chinese culture. Therefore, both leadership style questionnaires were used in this study. An ancillary outcome of this study will be a comparison of responses to the Eastern and Western instruments.

\section{Method}

\section{Research Design}

A quantitative survey methodology and qualitative interview methodology was used in this study. The reason for using the mixed methodology was to adequately explore the relationship between leadership concepts in different cultures. This was accomplished using the Multifactor Leadership Questionnaire (MLQ-5X), the Transformational Leadership Questionnaire (TFLQ), the Transactional Leadership Questionnaire (TSLQ), open-ended questions, and face-to-face interviews.

The questionnaires were used for deductive quantitative analysis. Each questionnaire has documented reliability and validity, and the appropriate permissions were obtained. The researcher also performed inductive analysis by using qualitative open-ended questions and interview methodology to develop the details of leadership styles since this methodology offers a more explicit description of people's thoughts.

\section{Participants}

This non-parametric study involved the entire population of 27 public and 30 private Taiwanese universities. The potential participants included 57 directors and 285 followers (5 followers for each director) for the quantitative data collection and six interviewees were purposively selected from all followers after quantitative data analysis identified directors with transformational leadership styles from different geographic locations of Taiwanese universities.

Each of the 57 directors was asked to complete the MLQ-5X leader form. The 285 followers were asked to evaluate his or her respective director using the MLQ$5 \mathrm{X}$ rater form, the TFLQ, the TSLQ, and the open-ended response sections of the questionnaires.
These followers were invited to participate in an interview process. The criteria for selection is both director and followers indicated a consistent tendency of transformational leadership behaviors from MLQ-5X leader form and rater form, TFLQ, and TSLQ.

All the survey responses were anonymous and confidential; no names or identifying marks were placed on the questionnaires, only a series of numbered codes was used to identify the institutions for tests of quality, reliability and validity. This study focused only on universities so as to serve as a model study that could later be applied to other institutions of the same academic level.

\section{Instruments}

Multifactor Leadership Questionnaire (MLQ$5 X$ short form, Chinese version). There were 45 items included in the newly revised version of the MLQ-5X (Bass \& Avolio, 2000), which is comprised of both leader and rater forms. The MLQ-5X included three leadership styles and three outcome factors. The three leadership styles were transformational, transactional, and laissez-faire. The nine leadership scale components included: idealized influence (attributed charisma), idealized influence (charismatic behavior), inspirational motivation, intellectual stimulation, individual consideration, contingent reward, managementby-exception (active), management-by-exception (passive), and laissez-faire leadership behaviors. The three outcomes included: followers' extra effort, organizational effectiveness, and followers' satisfaction with their leader.

The preliminary reliabilities for the total 45 items of the nine leadership scales ranged from .74 to .94 . An intercorrelation of .64 to .92 was identified for the sixfactor model but did not include the outcome factors (as cited in Bass \& Avolio, 2000). The range of each of the 45 items was rated on a 5-point scale from 0 (not at all), 1 (once in a while), 2 (sometimes), 3 (fairly often), to 4 (frequently, if not always).

Transformational Leadership Questionnaire (TFLQ). This questionnaire was designed by $\mathrm{Wu}$ and Lin (1998) and used open-ended items to collect the transformational leadership behavior and transactional leadership behavior information for the leaders' characteristics from samples of businesses and schools. This questionnaire was based upon Bass's theory and factor analysis of a pilot study 
to develop the Transformational Leadership Questionnaire and Transactional Leadership Questionnaire for Chinese managers.

There were 35 items included in the seven subfactors that make up the transformational theory factor for the TFLQ. The theory factors are charisma or idealized influence, inspirational motivation, intellectual stimulation, and individual consideration. The seven subfacors are close harmony, vision attraction, commitment and justice, inspired to vision, respected trust, intellectual stimulation, and individual consideration. The Cronbach alpha coefficient for the TFLQ evidenced an internal consistency reliability of .97 for the full-item scale and a Cronbach alpha coefficient range of .83 .91 for each factor scale. Each of the 35 items was rated on a 5-point scale from 0 (not at all), 1 (once in a while), 2 (sometimes), 3 (fairly often), to 4 (frequently, if not always).

\section{Transactional Leadership Questionnaire (TSLQ).} This questionnaire was designed at the same time as the TFLQ by $\mathrm{Wu}$ and Lin (1998). There are 30 items which include five subfactors in the TSLQ. The two theory factors are contingent reward and management-by-exception. The five subfactors included four theory subfactor and plus another factor that the researchers found to be specific to Chinese culture.

The Cronbach alpha coefficient was .85 for the fullitem scales and a Cronbach alpha coefficient range of .78 .89 for each factor scale for the internal consistency of reliability on the TSLQ. Each of the 30 items was rated on a 5-point scale from 0 (not at all), 1 (once in a while), 2 (sometimes), 3 (fairly often), to 4 (frequently, if not always).

Researcher. Open-ended questions and face-to-face interviews were used for qualitative data in this study. The researcher was the primary instrument. Trustworthiness of the work was dependent upon the transferability (validity) and the dependability (reliability) of the study. Credibility was demonstrated through triangulation and member checking strategies to ensure internal validity and reliability. The triangulation strategies included data triangulation and methods triangulation of thick description for external validity (Patten, 1990; Patton, 1990; Merriam, 1998).
The data triangulation strategies included the use of multiple sources, which included the open-ended question responses and face-to-face interview information. The different quantitative and qualitative data collections were the methods triangulation strategies. Member checking strategies were used after transcription of interview records, which were sent to the six interviewees for verification.

The validity of qualitative research is usually referred to as plausibility, credibility, trustworthiness or defensibility. The researcher, as the primary instrument in the qualitative phase of this study, developed inductive understanding of data through the nature of detail from interviewees and avoided personal biases to search for evidence about cause and effect. The researcher had to avoid bias when recording information and not allow personal views or perspectives to affect the participants during the interviews or while analyzing the research data (Patten, 1990, p. 119).

There are two open-ended questions in the survey questionnaire.

- Normally, how would you describe the leadership style and characteristics of the current director in your Physical Education Department?

- How does your current Physical Education Department director direct his/her requests for actions to you? How does he/she respond to or manage when requests are not being completed?

\section{Data Collection}

There were five steps in the data collection procedure. First of all, 57 Taiwanese university Physical Education Offices were identified. These involved 27 public and 30 private universities.

Third, the questionnaires were to be returned after two weeks; otherwise, a phone call would be made to make sure the Physical Education Offices received the package from the researcher. A research package would be sent again if the Physical Education Offices had not received the package. 
Fourth, six followers of Physical Education Office followers are purposive sampling for the face-to-face interviews. A research package was sent to the selected participants, which included the interview protocol and an informed consent letter. A phone call was made to set up an appointment with each interview participant. The researcher asked permission to take notes and use a tape recorder during the interviews to ensure accuracy of data collection. The participants were instructed they could request to turn off the tape recorder if they felt uncomfortable at any time.

Fifth, all of the interview contents were transcribed after the interview and the text was mailed to the interviewees to confirm the data.

\section{Data Analysis}

The quantitative data from this study were analyzed using the Statistical Package for the Social Sciences 10.0 (SPSS 10.0), which included descriptive statistics and Spearman rank correlations. The alpha was set at .05 $(\alpha=.05)$ and the confidence level was $95 \%$.

The Cronbach alpha coefficient was used first to ensure the internal consistency reliability of the MLQ-5X of the Chinese traditional character version, TFLQ, TSLQ.

The descriptive statistics were used on the demographic data and included means, standard deviations (SD), and percentages to describe the current leadership of Physical Education Offices in Taiwanese universities.

The Spearman rank correlation was applied for the relationship between different leadership instruments (MLQ-5X, TFLQ, and TSLQ).

The qualitative data analysis contained three parts for the research question \#2. These three parts are strategies of coding analysis, content analysis, and final analysis. The researcher would confirm the accuracy of the qualitative data before beginning the data analysis. The confirmation steps included checking the open-ended question response transcriptions, checking notes completed for the interviews, and having interviewees confirm the transcriptions.

The strategies of analyzing open-ended questions and interviews included analysis of the frequency of similar descriptive sentences and analysis of all the descriptive sentences to identify common themes.
The content analysis consisted of coding and categorizing the data. The data coding system depended upon the abbreviation of each frequent and similar sentence for following content data analysis. All of the content data were separated into different categories and subcategories in the data collection process.

Through analysis and interpretation the researcher clarified and conceptualized the data collected.

\section{Results}

The reliability of instruments was determined using the Cronbach alpha coefficient for questionnaires. In this study, the reliabilities for MLQ-5X items ranged from .38 to .91. No self-ratings were included for all of the above reliability reports. The reliability of the TFLQ was .98 (range from .88 to .96 ). The reliability of the TSLQ was .91 (range from .83 to .92$)$.

The qualitative data analyses encompassed strategies of analyzing, and content analysis for the open-ended questions and interviews. The strategies of analyzing included analysis of the frequency of similar descriptive sentences, which in turn identified common themes. The content analysis included coding and categorizing the data.

\section{Comparative Leadership Styles between Different Instruments}

Different instruments in this study including the MLQ-5X, the TFLQ, and the TSLQ evaluated the leadership styles. Ninety percent of the universities (28 out of 31) showed a higher frequency of transformational leadership (TFL) behaviors $(\mathrm{M}=3.07, \mathrm{SD}=.34), 6 \%$ of the universities (2 out of 31) showed a higher frequency of transactional leadership (TSL) behaviors $(\mathrm{M}=2.62$, $\mathrm{SD}=.42$ ), and one of the private universities had the same frequency of transformational and transactional leadership behaviors according to MLQ-5X leader form. Most directors self-rated themselves as transformational leaders. On the other hand, seventy-seven percent of the universities (30 out of 39) also showed a higher frequency of transformational leadership (TFL) behaviors, and fifteen percent of universities (6 out of 39) showed a higher frequency of transcational leadership (TSL) behaviors (see Figher 1). 
Figure 1. Current leadership styles in Physical Education Offices.

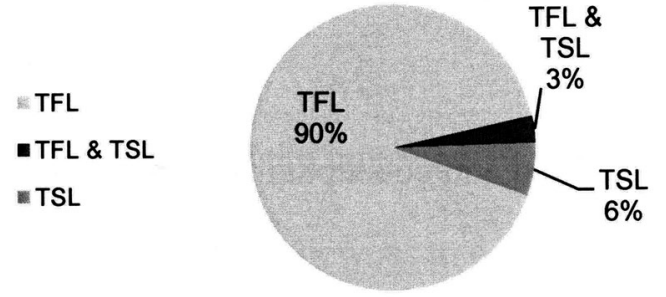

MLQ-5X (Leader Form)
: TFL

- TFL \& TSL

ETSL

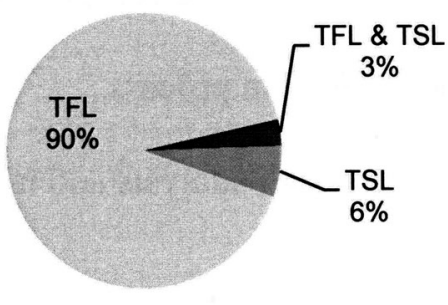

MLQ-5X (Rater Form)
The TFLQ and TSLQ, which were designed by Taiwanese authors, also determined the frequency of transformational leadership (TFL) and transactional leadership behaviors (TSL) of directors as rated by their followers. Seventy-four percent of the universities (29 out of 39) showed a higher frequency of transformational leadership behaviors, and $26 \%$ of the universities (10 out of 39) showed a higher frequency of transactional leadership behaviors (see Table 1).

Table 1. TFLQ/TSLQ Follower Results: Leadership Styles in Physical Education Offices.

\begin{tabular}{llll}
\hline Leadership behaviors & M & SD & Total $(\mathrm{n}=39)$ \\
\hline Transformational leadership & 2.49 & 0.84 & $29(74 \%)$ \\
Transactional leadership & 2.09 & 0.54 & $10(26 \%)$ \\
\hline
\end{tabular}

There was a significant positive correlation ( $\mathrm{rs}=$ $.81, \mathrm{p}<.01$ ) between transformational leadership (MLQ$5 \mathrm{X}$ rater form) and transformational leadership behaviors based on the TFLQ results. The transactional leadership of MLQ-5X rater form also had a significant positive correlation ( $\mathrm{rs}=.47, \mathrm{p}<.01$ ) with transactional leadership behaviors based on the TSLQ results (see Table 2).

Table 2. Spearman Rank Correlation Between Leadership of Different Instruments.

\begin{tabular}{|c|c|c|c|c|c|c|}
\hline \multirow[b]{2}{*}{ Leadership } & \multirow[b]{2}{*}{ style } & \multicolumn{3}{|c|}{ MLQ-5X } & \multirow{2}{*}{$\begin{array}{l}\text { TFLQ } \\
\text { TFL }\end{array}$} & \multirow{2}{*}{$\begin{array}{l}\text { TSLQ } \\
\text { TSL }\end{array}$} \\
\hline & & TFL & TSL & LFL & & \\
\hline & TFL & - & $.59 * *$ & -.14 & $.81^{* *}$ & $.38 * *$ \\
\hline \multirow[t]{2}{*}{ MLQ-5X } & TSL & & - & .08 & $.46^{* *}$ & $.47 * *$ \\
\hline & $\mathrm{LFL}$ & & & - & $-.27 * *$ & $.24 *$ \\
\hline TFLQ & TFL & & & & - & $.35^{* *}$ \\
\hline TSLQ & TSL & & & & & - \\
\hline
\end{tabular}

Note. MLQ-5X = Multifactor Leadership Questionnaire (Form 5X); TFL = transformational leadership;

TSL = transactional leadership; LFL = laissez-faire leadership; TFLQ = Transformational Leadership Questionnaire;

TSLQ = Transactional Leadership Questionnaire. $\mathrm{n}=102$.

$* \mathrm{p}<.05$, two-tailed. $*$ * $\mathrm{p}<.01$, two-tailed. 
This study showed a positive correlation between transformational and transactional leadership styles within each pair of instruments. Furthermore, Table 2 shows the transformational leadership behaviors based on the MLQ$5 \mathrm{X}$ follower results were found to have a significant positive correlation with both transactional leadership behaviors based on the MLQ-5X follower results ( $\mathrm{rs}=$ $.59, \mathrm{p}<.01$ ), and the transactional leadership behaviors based on the TSLQ results $(\mathrm{rs}=.38, \mathrm{p}<.01)$. The transactional leadership behaviors based on the MLQ$5 \mathrm{X}$ follower results also had a significant positive correlation with the transformational leadership behaviors based on the TFLQ results ( $\mathrm{rs}=.46, \mathrm{p}<.01)$. The transformational leadership behaviors based on the MLQ-
5X follower results had a significant positive correlation with transactional leadership behaviors based on the TSLQ results $(\mathrm{rs}=.35, \mathrm{p}<.01)$ in this study.

Moreover, there was a consistent tendency of leadership styles, even among leadership styles determined by the different evaluative instruments. The frequency for leadership style obtained similar results for transformational leadership (TFL) $(\mathrm{M}=2.45, \mathrm{SD}=.61)$ and transactional leadership (TSL) $(\mathrm{M}=2.09, \mathrm{SD}=.47)$ based on the Multifactor Leadership Questionnaire (MLQ-5X rater form), the Transformational Leadership Questionnaire (TFLQ) $(\mathrm{M}=2.49, \mathrm{SD}=.84)$, and the Transactional Leadership Questionnaire (TSLQ) $(\mathrm{M}=2.09, \mathrm{SD}=.54)$ (see Figure 2).

Figure 2. The frequency of transformational leadership and transactional leadership styles in different evaluative questionnaires.

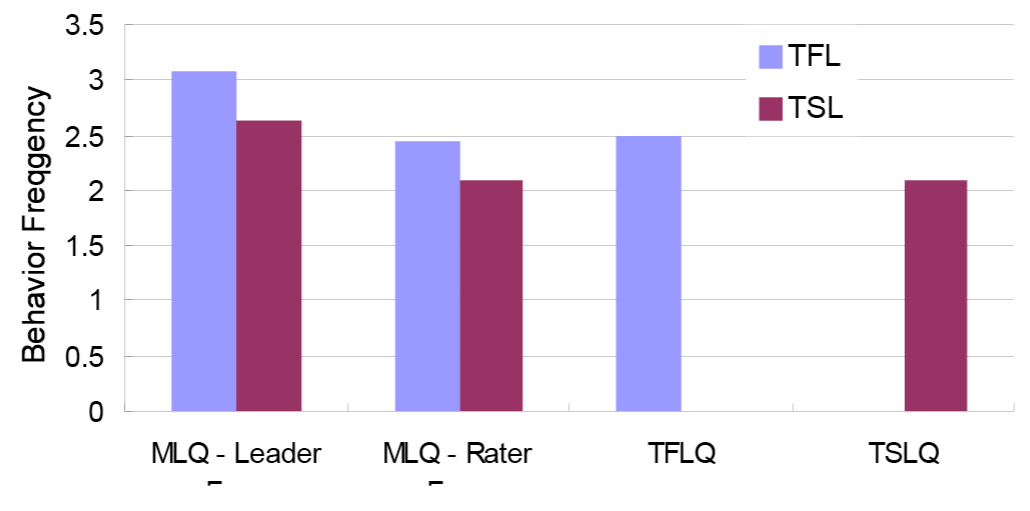

\section{Qualitative Data Collection Findings}

There were nine categories classified for the current Physical Education Offices' leadership behaviors and characteristics from 51 participants who responded to the first open-ended question. The nine categories were: vision, positive thinking and responsibility, assistance (individual consideration), democracy, trust and empowerment, communication, failure to take action, lack of communication, autocracy, and conservative and passive reaction. Such as, both A46 and A31 said the director shared the vision with followers and tried to build prestige for the Physical Education Office. "He is bold, open-minded, and seeks the office's benefit" (A159, personal communication).

There were 48 participants who responded to the second open-ended question, which focused on the leadership behaviors when directors requested action from their followers. The categories of the second question included communication and support, clear goals and purpose, defined schedules, empowerment, direction, encouragement and praise, anger, and no-response. Many respondents said their directors communicated with and supported them when requesting a task or an action.

Six followers who were purposively sampled according to primary quantitative data analysis from 21 universities. The 21 universities showed a higher frequency of transformational leadership behaviors from the returned questionnaires.

The first follower interviewed stated about her office leader, "He is a positive and responsible director" (\#1, personal communication). He was not argumentative or punitive and thereby maintained a good relationship with his followers. He communicated well with me; however, he had some problems communicating with people in higher positions because of his straightforward personality. 
\#2 expressed that he had been taught much through his various administrative experiences. He had 15 years of experience in administrative work. He had known the current Physical Education Office director for almost 13 years and had been a colleague of his for four years. He was glad he could work with a responsible and empowering director. The director only got involved with his followers during task implementation when they overstepped their boundaries of responsibility. The director always reminded the followers to effectively use all resources, including human. The director also told his followers that they were a team and they did not have to struggle alone. \#2 said that he enjoyed working and learning through experiences with his director because his director inspired him and encouraged him to plan well and to finish a task before the due date. His director also reminded his followers of the key points for task completion, and supported their efforts.

\#2 also expressed his feelings about both the previous and current director, and their reactions to incomplete tasks. The previous director was always angry and punished the followers for incomplete work. The followers felt frustrated and sometimes doubted their work ability. The current director always encouraged the followers, helped them and gave them suggestions to improve their work. He would have a personal discussion with each follower whenever the task was not finished. The director would always say, "you did a good job" or "you can do better" (\#2, personal communication).

"I have grown through learning and improved my ability to deal with affairs. I have expanded my thoughts and increased my social relationships by participating in the administrative work" (\#3, personal communication). \#3 had four years of work experience with the current Physical Education Office director. She said that her director liked to share his vision and ideas with colleagues. The director was a perfectionist and also asked for quality from his followers because he had high personal goals and great expectations for the Physical Education Office. However, he was modest when requesting a task, discussing it with his followers and supporting them while they carried it out.

The director would praise his followers in a group or in a meeting when the task was finished. He would help finish incomplete work instead of being angry or punishing his followers. As \#4 expressed, the current director liked to share his personal experiences with his followers. The director acquired his administrative work experience from his previous teaching assistant position and as the current director of the Physical Education Office. He thought he could improve and expand his administrative ability through participation in administrative work and he encouraged his followers to develop their work experiences and abilities.

She considered the relationship with her director as a partnership, not as a "leader" and "follower" (\#5, personal communication). \#5 said he was not only a director, but he was also open-minded and participated in the activities of her office.

The director was concerned about both the individual as well as the atmosphere of the office, according to \#6. The interviewee was impressed by the director's optimism. The director was always saying "by laughing three times every day you will keep happiness in the work place" (\#6, personal communication).

\section{Dissussions}

Many research studies have confirmed that transformational leadership is more active and effective than transactional leadership; however, an effective leader combines both types of leadership behaviors and displays them in different amounts in different situations.

Fifty-seven Taiwanese universities were asked to participate in this study: 27 public universities and 30 private universities. The response rate of director selfrating was 54\% (31 out of 57), and followers was 68\% (39 out of 57). When considering response rates, "at least 50 percent is generally considered adequate for analysis and reporting, a response rate of at least 60 percent is considered good and a response rate of 70 percent or more is very good" (Babbie, 1990, p. 182).

Nunnally (1978) suggested that the reliabilities of Cronbach alpha coefficient were above the acceptable minimum of .70 for new measures. Although "no simple generalizations could be made about how much reliability is enough" (Smith, 1987, p.106); from reliability by a meta-analysis of two hundred articles and theories of reliability coefficient and variance analysis, Wu (1984) identified the following range for the coefficient alpha: between $.40-.50$ is a little reliable, and between $.50-.70$ is reliable. The reason for the lower MLQ-5X reliabilities for 
some scales may be the translated questionnaire, which was translated word for word from English to Chinese and therefore did not account for cultural differences. Also, different concepts in Eastern and Western cultures were, perhaps, not considered. However, the MLQ-5X rater form and the TFLQ/TSLQ had similar frequency scores and showed a similar trend for both transformational leadership and transactional leadership behaviors. This implies that the MLQ-5X may not be culture-dependent. Furthermore, similar results indicated that both the MLQ$5 \mathrm{X}$ and the TFLQ/TSLQ were effective in the Taiwanese environment.

Burns (1978) distinguishes transactional leadership and transformational leadership as two basic leadership behaviors. Bass (1985) sees both of these leadership behaviors on a continuum of leadership behaviors in the Full-Range of Leadership Model (Bass \& Avolio, 1994). An optimal leadership has a higher frequency of transformational leadership behaviors. This is an effective and active leadership style. House et al. (1999) and House, Hanges, Javidan, Dorfiman, \& Gupta (2004) provides important empirical evidence for the universal perspective and application on the effectiveness of transformational behavior (as cite in Spreitzer, Perttula, \& Xin, 2005), which means a fundamentally applicable conceptualization of meanings and variances (Hooijberg \& Choi, 2000). However, the culture impacts on leadership behaviors and it cannot be considered separately among them (Matviuk, 2010).

Table 3 shows the exhibiting character of the transformational leaders by a meta-ethnographic analysis (Pielstick, 1998), the qualitative data analysis of these study findings, and initial development of the TFLQ. The meta-ethnographic analysis, developed from numerous leadership literatures, focuses on transformational leadership. This includes shared vision and values, charisma, selfconfidence, passion, intelligence, a need for achievement, a practice and support of lifelong learning, a broad perspective, and some characteristics that affect shared vision. The TFLQ scale included characteristics such as close harmony, an attractive vision, commitment and justice, an inspiration to vision, respect and trust, intellectual stimulation, and individual consideration.

The transformational directors of Physical Education Offices exhibited characteristics such as respect, fairness, honesty, confidence and a positive attitude. They were responsible, modest, tolerant and understanding, passionate, open-minded, logical in their thinking, optimistic, dynamic, loyal, and bold; they also had integrity and a straightforward personality.

Traditional Chinese values are influenced by the ancient Confucian thinking, which emphasizes social reform and personal transformation (Koller, 2002). Chinese values seem to be exhibited in the transformational leadership behaviors in the Physical Education Offices of Taiwanese universities.

The transformational directors of Physical Education Offices expressed teamwork with their followers. They had good communication and good relationships with others whom they empowered. They encouraged themselves and their followers to learn, be concerned, listen to, support and accept ideas. It is through these transformational leadership behaviors that the followers gained confidence and worked hard to achieve the office's vision. Teamwork was one characteristic of transformational leadership that appeared in this study's results.

In the United States, leadership is more individualistic; "...leadership is viewed as an individual activity that is accessible to (almost) everyone and that is rich in challenge, change, active learning, and selfimprovement" (Hoppe, 1998, p. 345). In countries that are more collective, such as China and Japan, leadership is expressed through the development of the group even though it includes the individual desire (Hoppe, 1998). Although the transformational directors had personal goals and great expectations for their Physical Education Office, they still placed the benefits for their offices before their own personal interest.

Praise and reward also appeared in the transformational leadership style in this study. Praise and reward belong to the contingent reward aspect of the transactional leadership style; however, the transformational leadership style does not replace the transactional leadership style in the Full-Range of Leadership Model but exhibits different amounts of each aspect (Bass \& Avolio, 1994). The Chinese culture values harmony with others, good relationships with others, and humanism. In this study, one of the ways that transformational directors seemed to encourage motivational behavior in their followers was through praise and reward. They praise individuals verbally in a group or through a meeting, and give rewards such as flexible work schedules or days off and good scores on annual evaluations. The 
transformational directors did not use praise or reward as an "exchange" with their followers, but they encouraged their followers when they did a good job. Chinese culture seems more tend to keep high harmony culture within in-groups than Western culture (Dong \& Liu, 2010) also find in this study.

Overall, from the results of the literature metaethnographic analysis, study findings, and the TFLQ, it seems that the transformational directors' characteristics can be generally separated into: personal wisdom, personality, and attitudes toward people and tasks. The transformational directors exhibited self-confidence and a broad perspective, which reflected their intelligence. They had personality traits such as honesty, integrity and trustworthiness, and showed a tolerant, passionate, friendly and warm attitude with respect to people. They show concern and understanding and are positive and optimistic about tasks. All of these transformational leaders' characteristics seemed to be similar, no matter what their culture.

\section{Table 3. Exhibiting Characteristics Between Literature, Qualitative of Study Findings, and TFLQ.}

\begin{tabular}{|c|c|c|}
\hline $\begin{array}{c}\text { A meta-ethnographic analysis: } \\
\text { Literatures (Dean Pielstick, 1998) }\end{array}$ & Qualitative of Study findings & TFLQ \\
\hline $\begin{array}{l}\text { - Shares vision and values: } \\
\text { Honesty, integrity, trust, fairness, } \\
\text { equality, dignity, respect for } \\
\text { others } \\
\text { - Charisma: Focus on the shared } \\
\text { purpose or vision } \\
\text { - Have a need for achievement, but } \\
\text { not for affiliation: Personable, } \\
\text { caring, friendly, warm } \\
\text { - Passionate: } \\
>\text { Focused and committed to the } \\
\text { shared vision } \\
>\text { Disenchanted with the status quo } \\
>\text { Pursued with a sense of giving } \\
\text { - To affect the shared vision: } \\
>\text { Energy, drive, stamina, dynamic, } \\
\text { practice wellness habits, have } \\
\text { contagious positive spirit, and } \\
\text { make the followers work hard. } \\
>\text { Love work, people, life } \\
>\text { Unwarranted optimism and } \\
\text { incurable idealism }\end{array}$ & $\begin{array}{l}\text { - Passion } \\
\text { - Concerned, listens, show } \\
\text { support and acceptance of } \\
\text { ideas } \\
\text { - Encourage } \\
\text { - Tolerant and understanding } \\
\text { - Optimistic } \\
\text { - Dynamic } \\
\text { - Good relationship with } \\
\text { Others } \\
\text { - Make followers confidence } \\
\text { and work hard }\end{array}$ & $\begin{array}{l}\text { - Close harmony: } \\
\text { Friendly, smiles, humor, warm } \\
\text { - An attractive vision: } \\
\text { Vision, clear goal, strong } \\
\text { motivation and achievement, } \\
\text { confidence, charisma, great } \\
\text { expectations } \\
\text { - Commitment and justice: } \\
\text { Works hard, is fair, resolute, } \\
\text { responsible, honest, shows } \\
\text { dignity } \\
\text { - Inspiration to envision: } \\
\text { Shares vision, creates } \\
\text { opportunities, encourages } \\
\text { performance and achievement, } \\
\text { inspires a common goal, role } \\
\text { model } \\
\text { - Respected trust: } \\
\text { Respect professional area, } \\
\text { empowerment, trust, respect } \\
\text { different ideas, communicate } \\
\text { and discuss for a consensus of } \\
\text { ideas, support }\end{array}$ \\
\hline
\end{tabular}

- Self-confidence: Committed and motivated, self-understanding and self-disciplined, empowering

- Intelligence:

- Confidence

- Good communication

- Positive and responsible

- Empowering

- Modest

Good judgment, have professional expertise leadership, cognitive complexity

- Broad perspective:

$>$ Awareness of complexities, systemic connections, patterns, and situation

$>$ Well-rounded

$>$ Open, unbiased, flexible with a tolerance for ambiguity and uncertainty, altruistic, generous $>$ Willingly sacrifice for their higher purpose

- Intellectual stimulation: Considerate, encourage learning and help followers growth, open-minded, design a creative environment, share experiences, continue learning

- Individual consideration: Concern, help solve problems, tolerance, allowance, understanding, caring 


- Practice and support lifelong
learning:

"All societies share the same problems, but different societies have found different answers to these problems" (Hofstede, 2001, p. 353). The transformational leadership leadership behaviors are universal and applications of these behaviors appear to be tailored to national differences (Boehnke, Bontis, DiStefano, \& DiStefano, 2003).

Table 4 shows the behavioral indicators of transformational leadership from the qualitative data study findings and Bass and Avolio's research (as cited in Chemers \& Ayman, 1993, p. 56), which included interviews with managers in a large European multinational firm. These behaviors were exhibited through the characteristics of the transformational leaders.

Jones and Rudd (2008) indicated that women and people of coloe utilize the same leadership styles as withe men in their study. The same leadership concepts may have contained specific thoughts, beliefs, understandings, or behaviors in one culture but not another; however, the concepts of transformational leadership may seem similar in different cultures but may be expressed differently.

Table 4. Comparison of Behavioral Indicators of Transformational Leadership.

\begin{tabular}{|c|c|}
\hline Bass \& Avolio's research (1993) & Study findings \\
\hline \multicolumn{2}{|c|}{ Charisma \& Inspiration } \\
\hline $\begin{array}{l}\text { - Addresses crises and faces them } \\
\text { - Transmits a sense of mission } \\
\text { - Presents an optimistic and attainable view of the } \\
\text { future (vision) } \\
\text { - Provides meaning for actions } \\
\text { - Appeals to the hopes and desires } \\
\text { - Seeks organizational benefit rather than personal } \\
\text { interest } \\
\text { - Sets a goal for followers to strive toward } \\
\text { - Raises expectations to challenge followers } \\
\text { - Encosses dedication to followers } \\
\text { - Makes opportunities for followers to take advantage of } \\
\text { - Eases group tension in critical times" }\end{array}$ & $\begin{array}{l}\text { Enthusiastic to share visions and ideas, and builds } \\
\text { prestige for the Physical Education Office } \\
\text { - High personal goals and great expectations for the } \\
\text { Physical Education Office } \\
\text { - Sets clear short, middle, and long-term goals; and } \\
\text { sets up a time schedule and makes readjustments in } \\
\text { the follow-up } \\
\text { - Expresses a task through meeting } \\
\text { - Presents positive attitude and is responsible } \\
\text { - Honest and just: Keeps his promises } \\
\text { - Empowers, and expresses teamwork } \\
\text { - Enthusiastic and optimistic } \\
\text { - Encourages followers to develop professional } \\
\text { knowledge and skill }\end{array}$ \\
\hline
\end{tabular}

- "Eases group tension in critical times" Intellectual Stimulation

- Encourages followers to reexamine and revisit their task or problems

- Shares experiences to apply to current problems

- Creates a "readiness" for changes in thinking

- Offers different perspectives on a problem

- Listens and accepts ideas
- Reminds followers to effectively use all resources, including human.

- Shows concern to, discusses with, and supports

- Shares personal experiences with followers

- Logical thinking and open-minded

- Likes teamwork and achieves this through open expression and discussion of the task

- Believes that discussion is an important way to gain a consensus of ideas, and accepts opinions and suggestions

- Helps followers to solve problems 


\section{Individual Consideration}

- Understands individual advantages and disadvantages, assigns a task according to individual ability and needs

- Encourages discussion of opinions

- Promotes self-development

- Shows interest in the well-being of others
"Trusts, supports, and empowers"

- Considers and respects the followers' professional knowledge and needs

- Praises in front of the other followers

- Rewards when the work is done

- Verbally encourages: "you did a good job" or "you can do better"

- Is concerned about both the individual as well as the atmosphere of the office

- Is happy to help others and shares optimistic attitude with followers: "by laughing three times everyday you will keep happiness in the work place"

Note. Bass \& Avolio 1993 research as cited in Chemers \& Ayman, 1993.

\section{Conclusions}

Overall, the conclusion included three points that emerged from the research findings and discussion. An overall important finding consistent in all of the quantitative data analysis was that there was little, if any, difference between public and private universities. This enhances the generalizability and transferability of study results to nonrespondent universities. The summarized conclusions were the following:

First, 90\% of universities presented higher frequencies of transformational leadership behaviors by the directors' self-rating on their own leadership style. More than $70 \%$ of universities presented higher frequencies of transformational leadership behaviors from the followers' rating through MLQ-5X (rater form) and the TFLQ on their current Physical Education Offices directors in Taiwanese universities. Although the directors' selfrating of leadership had a higher frequency score than the followers' ratings except for the laissez-faire scale, a consistent tendency of leadership behaviors was found even among the different evaluators and different MLQ-5X, TFLQ, and TSLQ leadership evaluation questionnaires in this study. Similar results indicated that both the MLQ-5X (rater form) and the TFLQ/ TSLQ were effective in the Taiwanese environment. This implies that the MLQ-5X may not be culturedependent.
Second, the transformational directors of Physical Education Offices exhibited personal characteristics such as: respect, fairness, honesty, confidence, a positive attitude, responsibility, modesty, tolerance and understanding, passion, open-mindedness, logical thinking, optimism, dynamic personality, integrity, loyalty, boldness, and a straightforward personality. They always honored their word and kept their promises

Transformational leadership behaviors displayed between directors and their followers were: good relationships and communication with others, empowerment, encouragement, concern, listening and support, praise and reward, and accepting ideas from others. Through these leadership behaviors, followers felt confidence, and worked hard to achieve the office's vision. Moreover, teamwork was found in the Physical Education Offices as a result of the transformational leadership behaviors. The same leadership concepts may have contained specific thoughts, beliefs, understandings, or behaviors in one culture but not another; however, the concepts of transformational leadership may seem similar in different cultures but may be expressed differently.

Third, although transformational and transactional leadership styles include universal concepts and MLQ-5x are effective in the Taiwanese environment, the overlap of leadership behaviors were never solved. 


\section{References}

Avolio, B. J., Bass, B. M., \& Jung, D. I. (1999). Reexamining the components of transformational and transactional leadership using the Multifactor Leadership Questionnaire. Journal of Occupational and Organizational Psychology, 72(4), 441-456.

Avolio, B. J., Waldman, D. A., \& Yammarino, F. J. (1991). Leading in the 1990s: The four I's of transformational leadership. Journal of European Industrial training, 15(4), 9-16.

Babbie, E. R. (1990). Survey research methods (2nd ed.). Belmont, CA: Wadsworth.

Bass, B. M. (1985). Leadership and performance beyond exceptions. New York: Free Press.

Bass, B. M. (1995). Comment: Transformational leadership. Journal of Management Inquiry, 4(3), 293-297.

Bass, B. M. (1997). Does the transactional-transformational leadership paradigm transcend organizational and national boundaries? American Psychologist, 52(2), 130-139.

Bass, B. M., \& Avolio, B. J. (1993). Transformational leadership: A response to critiques. In M. M. Chemers, \& R. Ayman (Eds.), Leadership theory and research: Perspectives and directions (pp. 49-80). San Diego, CA: Academic Press.

Bass, B. M., \& Avolio, B. J. (1994). Improving organization effectiveness through transformational leadership. Thousand Oaks, CA: Sage.

Bass, B. M., \& Avolio, B. J. (2000). MLQ multifactor leadership questionnaire (2nd ed.). Redwood, CA: Mind Garden.

Boehnke, K., Bontis, N., DiStefano, J. J., \& DiStefano, A. C. (2003). Transformational leadership: An examination of cross-national differences and similarities. Leadership \& Organization Development Journal, 24(1), 5-15.
Burns, J. M. (1978). Leadership. New York: Haper \& Row.

Den Hartog, D. N., Van Muijen, J. J., \& Koopman, P. L. (1997). Transactional versus transformational leadership: An analysis of the MLQ. Journal of Occupational \& Organizational Psychology, 70(1), 19-34.

Dong, K., \& Liu, Y. (2010). Cross-cultural management in china. Cross Cultural Management, 17(3), 223-243. doi:10.1108/13527601011068333

Hofstede, G. H. (2001). Culture's consequences: Comparing values, behaviors, institutions, and organizations across nations (2nd ed.). Thousand Oaks, CA: Sage.

Hooijberg, R., \& Choi, J. (2000). From selling peanuts and beer in Yankee stadium to creating a theory of transformational leadership: An interview with Bernie Bass. Leadership Quarterly, 11(2), 291-306.

Hoppe, M. H. (1998). Cross-cultural issues in leadership development. In C. D. McCauley, R. S. Moxley, \& E. Van Velsor (Eds.), The center for creative leadership handbook of leadership development (pp. 336-378). San Francisco: Jossey-Bass.

Jones, D., \& Rudd, R. (2008). Transactional, transformational, or laissez-faire leadership" An assessment of college of agriculture academic program leaders'(Deans) leadershio styles. Journal of Agricultural Eductaion, 49(2), 88-97.

Koller, J. M. (2002). Asian philosophies (4th ed.). Upper Saddle River, NJ: Person Education.

Matviuk, S. (2010). A correlational study of culture and leadership expectations in a mexican manufacturing plant. The Business Review, Cambridge, 15(1), 14-19.

Merriam, S. B. (1998). Qualitative research and case study applications in education (Rev. ed.). San Francisco: Jossey-Bass.

Nunnally, J. C. (1978). Psychometric theory (2nd ed.). New York: McGraw-Hill. 
Patten, M. L. (1990). Understanding research methods: An overview of the essentials (2nd ed., pp.119-124). Los Angeles: Pyrczak.

Patton, M. Q. (1990). Qualitative evaluation and research methods (2nd ed.). London: Sage.

Pielstick, C. D. (1998). The transforming leader: A metaethnographic analysis. Community College Review, 26(3), 15-34.

Smith, M. L. (1987). Research and education in education and the social science. Englewood Cliffs, NJ: Prentice-Hall.

Spreitzer, G. M., \& Xin, K. (2005). Traditionality matters: An examination of the effectiveness of transformational leadership in the United States and Taiwan. Journal of Organizational Behavior, 26(3), 205-227.
Tejeda, M. J. (2001). The MLQ revisited: Psychometric properties recommendations. Leadership Quarterly, 12(1), 31-52.

Tracey, J. B., \& Hinkin, T. R. (1998). Transformational leadership or effective managerial practices? Group and Organization Management, 23(3), 220-236.

Wu，J. J., \& Lin，H. M. (1998). 轉型領導量表與交易領 導量表的建立 [The construction of transformational leadership questionnaire and transactional leadership questionnaire]. CAPT Psychological Testing, 45(2), 5787.

Wu, T. X. (1984). 電話調查: 理論與方法 [Telephone survey: Theories and methods]. 台北: 聯經.

\section{Correspondence:}

\section{Suh-Ting Lin}

Address: 151 Ying-chuan Road Tamsui,

Taipei 25137, Taiwan

5137 台北縣淡水鎮英專路151號

E-mail: school@ms19.url.com.tw

suh@mail.tku.edu.tw 